\title{
Is Consumption Growth Consistent with Intertemporal Optimization? Evidence from the Consumer Expenditure Survey
}

\section{Orazio P. Attanasio}

Stanford University, Università di Bologna, National Bureau of Economic Research, and Institute for Fiscal Studies

\section{Guglielmo Weber}

Università di Padova and Institute for Fiscal Studies

\begin{abstract}
In this paper we show that some of the predictions of models of consumer intertemporal optimization are in line with the patterns of nondurable expenditure observed in U.S. household-level data. We propose a flexible specification of preferences that allows multiple commodities and yields empirically tractable equations. We estimate preference parameters using the only U.S. micro data set with complete consumption information. We show that previous rejections can be explained by the simplifying assumptions made in previous studies. We also show that results obtained using good consumption or aggregate data can be misleading.
\end{abstract}

\section{Introduction}

In this paper, we show that some of the predictions of models of consumer intertemporal optimization are in line with the patterns of

An early and very different version of this paper was circulated at the end of 1992 and presented at the NBER Economic Fluctuation Conference in Cambridge, October 1992. We are grateful to John Cochrane, who discussed the paper, for very insightful comments and to several participants, and in particular to Angus Deaton, Janice Eberly, and Costas Meghir, who gave us very good suggestions. We also acknowledge helpful suggestions by two anonymous referees. This paper was completed while Attanasio was a National Fellow at the Hoover Institution. Attanasio's research was partially financially supported by National Science Foundation grant SES-9057511. Weber's research was part of the ESRC Functioning of Markets Initiative. 
nondurable expenditure observed in U.S. household-level data. Our results and our approach are new in several respects. First, we use the only U.S. micro data set that has direct and complete information on household consumption. The microeconomic data sets used in most of the consumption literature so far contained either very limited information on consumption (like the Panel Study on Income Dynamics [PSID]) or none at all, in which case consumption had to be obtained indirectly from income and changes in assets. Second, we present empirical results that show that it is possible to find a reasonably simple specification of preferences that controls for the effects of changes in demographics and labor supply behavior over the life cycle and is not rejected by the available data. Third, we propose a flexible and novel specification of preferences that is easily estimable and allows a general treatment of multiple commodities. We show that a proper treatment of aggregation over commodities can be important, both theoretically and in practice.

Our results contrast sharply with most of the previous evidence, which has typically been interpreted as rejection of the theory. Several papers in the last 15 years have used microeconomic data to establish the plausibility of the intertemporal optimization model. Hall and Mishkin (1982), for instance, find that consumption is excessively sensitive to lagged labor income. Zeldes (1989) finds excess sensitivity for low-wealth households and suggests that liquidity constraints are important for individuals in these households. ${ }^{1}$ Results based on aggregate time-series data, such as those in Flavin (1981) and Campbell and Mankiw (1989), suggest even stronger rejections.

In this paper we interpret previous rejections as evidence against some simplifying assumptions made to derive empirically tractable equations. In particular, we show the following results.

a) Aggregate data are particularly unsuitable to test the theory. Incorrect aggregation can lead to spurious rejections of the theory. Even in the simple case of isoelastic utility, aggregation can be troublesome, since the theory requires knowledge of the logarithm of consumption. We use our household-level data to assess the consequences of neglecting the nonlinearities implied by the model and find that theory restrictions can be rejected just because of an incorrect aggregation procedure.

b) Food consumption, which is often taken as a "proxy" for total nondurable consumption in studies using micro data, is unsuitable because preferences are nonseparable between food and other non-

\footnotetext{
${ }^{1}$ See also Carroll and Summers (1991), who observe that consumption tracks income over the life cycle. The papers by Meghir and Weber (1991), Runkle (1991), and Keane and Runkle (1992) are exceptions. Altonji and Siow (1987) appeal to measurement error to explain the rejections reported in some of these papers.
} 
durables, and food is a necessity. Furthermore, during the sample period, the relative price of food is far from constant. We show that the consequences of using food consumption rather than total nondurable consumption are nonnegligible: theory restrictions are rejected, and the elasticity of intertemporal substitution is poorly determined when food is used.

c) The allocation of total nondurable consumption over time is affected by predictable changes in both household composition and labor supply of individual household members. If this dependence is either neglected or poorly specified, evidence of excess sensitivity to labor income growth is produced.

We use a time series of cross sections (the Consumer Expenditure Survey, 1980-90) to construct consistently aggregated cohort-level data-a synthetic panel-in which households are grouped by year of birth and education. As discussed below, the availability of a relatively long time period is crucial in the estimation of Euler equations. Furthermore, thanks to the detailed information in the data set, we can construct different consumption measures, which include food and other nondurable commodities.

On our preferred specification, we obtain precise estimates of key behavioral parameters (including the elasticity of intertemporal substitution) and no rejections of theoretical restrictions.

The paper is organized as follows. Section II describes the data: it shows that income and consumption age profiles track each other. This could be due to myopic behavior (as pointed out by Carroll and Summers [1991]) but could also be explained by changes in demographics and leisure over the life cycle. Section III presents the basic intertemporal optimization model and discusses its empirical implementation. Section IV discusses econometric issues, with particular reference to the techniques used to estimate a dynamic relationship on a time series of repeated cross sections. The econometric techniques used are discussed in detail in the Appendix. Section V illustrates the effects of incorrect aggregation across consumers and presents estimates of preference parameters when consumption is defined as total nondurable expenditure, deflated by a standard price index, and the chosen specification allows for the effects of demographic and labor variables. Section VI shows that Euler equations based on food consumption are misspecified, if no attempt is made to control for the presence of other nondurable commodities. In Section VII, we describe in detail our specification of preferences, which allows for nonhomotheticity and nonseparability between goods and leisure while preserving empirical tractability, and we show that both the relative price of food and its share in nondurable expenditure have varied considerably over the 1980 s. Section VIII presents esti- 
mation results: Section VIIIA describes parameter estimates of a small demand system, which confirm the importance of nonhomotheticity, and Section VIIIB presents our estimates of the Euler equation implied by the specification of preferences presented in Section VII. Section IX concludes the paper.

\section{Consumption Behavior: Data and Descriptive Analysis}

Until recently, no micro data set contained complete information on U.S. household consumption. As stressed above, most of the empirical work on the life cycle model used the PSID, which contains only a measure of food consumption. Since 1980 the Bureau of Labor Statistics (BLS) has been running the Consumer Expenditure (CEX) Survey on a continuous basis. The survey is now available for 11 consecutive years, which include two recessions, a long expansion, and two major tax changes and witnessed substantial movements in relative wages and prices. The CEX is not a full panel (households are interviewed over four consecutive quarters and then replaced); however, because it is available over a relatively long time period and contains considerable demographic information, the use of synthetic cohort analysis allows the study of the evolution of consumption over the life cycle.

Therefore, the CEX gives, for the first time, the possibility of analyzing individual consumption behavior over the life cycle and over the business cycle. In the next section we present a structural model for nondurable consumption that is not rejected by the data and allows us to estimate some key behavioral parameters. Before doing so, however, we describe the main features of the data used in estimation.

\section{A. The CEX Survey}

The data we use cover the period 1980-90. In this subsection we describe the data and the main selection criteria used. The CEX is based on a comprehensive survey run by the BLS, which interviews about 4,500 households every quarter; ${ }^{2} 80$ percent of them are then

${ }^{2}$ The unit of reference is what the BLS Tape Manual defines as "consumer unit," which consists of "all members of a particular housing unit or other type of living quarters who are related by blood, marriage, adoption, or some other legal arrangement, such as foster children. Consumer unit determination for unrelated persons is based on financial independence. To be considered financially independent, at least two of the three major expense categories (food, housing, and other living expenses) have to be provided by the respondent." 
reinterviewed the following quarter, and the remaining 20 percent are replaced by a new, random group. Therefore, each household is interviewed at most four times over a period of a year. During the interviews, a number of questions are asked concerning household characteristics (demographics, work status, education, race, etc.) and detailed expenditures over the three months prior to the interview. The sample is representative of the U.S. population.

We exclude from our sample nonurban households, households residing in student housing, and households with incomplete income responses. Furthermore, as discussed below, we consider only households headed by individuals born after 1904 and before 1965 and that are at least 19 and no more than 75 years old. These exclusion restrictions leave us with a sample of 146,219 interviews. From each interview, in addition to the demographic and labor supply variables discussed below, we consider the expenditure figures for the month preceding the interview. The first two months of the quarter preceding the interview are excluded to avoid the fairly complicated error structure that the timing of the interviews would imply on quarterly data. $^{3}$

In what follows we consider various components of nondurable expenditure. In particular, for reasons to be discussed below, we look at food (defined as the sum of food at home, food away from home, alcohol, and tobacco) and expenditure on other nondurable goods and services, such as services, heating fuel, public and private transport (including gasoline), and personal care, and semidurables, defined as clothing and footwear. The major exclusions from total consumption expenditure are consumer durables, housing, health, and education expenditure.

Below we use two income variables: total after-tax family income and total before-tax "labor" income. Labor income is defined as total family income minus capital income. Unfortunately, it is not possible to reconstruct the after-tax labor income. ${ }^{4}$

The CEX contains a wealth of information on household characteristics and labor supply behavior. The demographic variables we examined in the empirical analysis are family size, number of children by age groups, number of adult members, number of persons older than 64, gender of the household head, the educational attainment of the reference person, and the marital status of the household head.

\footnotetext{
${ }^{3}$ Such a complication would arise because there are households interviewed in each month, and therefore their quarterly consumption would refer to overlapping periods.

${ }^{4}$ Income data are collected at the first and last interviews and refer to the previous 12 months. Labor income is also computed at the second or third interview if a member of the household reports changing his or her employment.
} 
The labor supply variables we have considered are various employment dummies, the number of earners, the number of hours worked by the wife, and the dummies for part-time and full-time female employment.

The demand system in Section VII is estimated for different groups, formed on the basis of the educational attainment of the household head. The first group includes high school dropouts, the second high school graduates, the third households with some college education, and the fourth college graduates. When all years are considered together, the four groups account for 22.7, 29, 22, and 26.3 percent of the total sample.

We devote a considerable amount of attention to the construction of appropriate price indices. Besides the parameters of the demand system discussed below, to construct such indices we need the prices of the commodities we model (food and other nondurables). These indices are constructed from the components of the Consumer Price Index published monthly by the BLS. These prices are regionspecific. The price indices for the composite commodities (food, other nondurables) that form our demand system are then constructed as expenditure share weighted averages of the elementary price indices. They are therefore household-specific.

To describe the intertemporal allocation of consumption, we also need a nominal interest rate. We choose the return on municipal bonds since it is tax-exempt, therefore avoiding the difficulty of measuring individual marginal tax rates. We have also experimented with the 3-month Treasury bill. Both interest rate series are taken from the Economic Report of the President.

\section{B. Life Cycle and Time-Series Variation}

In this subsection we describe the main features of the variables that are relevant for the more formal analysis of Section VI. In particular, we characterize the life cycle profile of nondurable consumption, household income, family composition, and female labor supply. In addition, we examine the time-series variability of prices and average consumption over the sample period under study. This analysis is useful not only as a descriptive tool but also as an indirect check on the quality of the data set, which is relatively new.

The main problem with using the CEX for the analysis of a dynamic model such as the life cycle one is that each household is not observed over a long period of time. However, the continuity of the survey allows us to follow the average consumption behavior of homogeneous groups over time, as they age. This is the main idea behind the synthetic cohort analysis, which is used both in this section 
and in the more structural analysis in Section VI. We divide the households in the sample into cohorts, defined on the basis of the year of birth of the household head. ${ }^{5}$ We then average the variables of interest over all the households belonging to a given cohort observed in a given year. If there are $N$ cohorts observed for $T$ years, this procedure gives us $N T$ observations. In table 1, we report the cohort definition, their age in 1980, and the average cell size. The same cohort definitions are used in Section $\mathrm{V}$ to construct quarterly times series.

The advantage of grouping by the year of birth rather than by age in studying life cycle behavior is obvious. One follows over time a group of individuals born in the same period and therefore coming of age at the same time. Estimating age profiles by pooling together several cross sections and grouping by age is potentially very misleading in the presence of cohort effects.

In figure 1, we plot average cohort log nondurable consumption (fig. $1 a$ ) and log income (fig. $1 b$ ) against age. Each connecting segment represents mean log income or consumption of a given cohort. Because cohorts are defined by a 5-year interval and the sample covers 11 years, each cohort overlaps with an adjacent cohort at six ages.

Both income and consumption are hump-shaped, peaking before retirement. Furthermore, consumption is considerably less variable than income: the standard deviation of the residuals obtained when first log consumption and then log income are regressed on a polynomial in age and cohort dummies is 0.04 and 0.06 , respectively. This difference could be explained by smoothing behavior or by greater measurement error in income than in consumption.

The fact that both consumption and income present a pronounced hump (and the fact that differences in the shape of income profiles among occupation groups were reflected by similar differences in consumption profiles) is interpreted by Carroll and Summers (1991) as evidence against the life cycle model. However, they ignore family composition. In figure 2 , we plot the age profile of family size. As can be seen, the age profile for family size is also hump-shaped. ${ }^{6}$

In figure 3, we plot the life cycle profile for female average annual hours of work. The average is conditional on the presence of the

\footnotetext{
${ }^{5}$ The household head is defined as the person who owns or signs the rental contract of the home in which the consumer unit lives. For married couples, however, we define the husband as the household head and therefore use his age to establish which cohort the household belongs to.

${ }^{6}$ There are also remarkable differences in the shape of family size across education and occupation groups. It is therefore possible that differences in consumption across education groups could be explained by differences in demographics. See the discussion in Attanasio et al. (1995).
} 
TABLE 1

Cohort Definition

\begin{tabular}{ccccc}
\hline \hline Cohort & Year of Birth & Age in 1980 & $\begin{array}{c}\text { Average Cell } \\
\text { Size }\end{array}$ & $\begin{array}{c}\text { Used in } \\
\text { Estimation }\end{array}$ \\
\hline 1 & $1960-64$ & $16-20$ & & no \\
2 & $1955-59$ & $21-25$ & 461 & yes \\
3 & $1950-54$ & $26-30$ & 460 & yes \\
4 & $1945-49$ & $31-35$ & 426 & yes \\
5 & $1940-44$ & $36-40$ & 321 & yes \\
6 & $1935-39$ & $41-45$ & 258 & yes \\
7 & $1930-34$ & $46-50$ & 241 & yes \\
8 & $1925-29$ & $51-55$ & 255 & yes \\
9 & $1920-24$ & $56-60$ & 272 & no \\
10 & $1915-19$ & $61-65$ & & no \\
11 & $1910-14$ & $66-70$ & & no \\
12 & $1905-9$ & $71-75$ & & \\
\hline
\end{tabular}

a

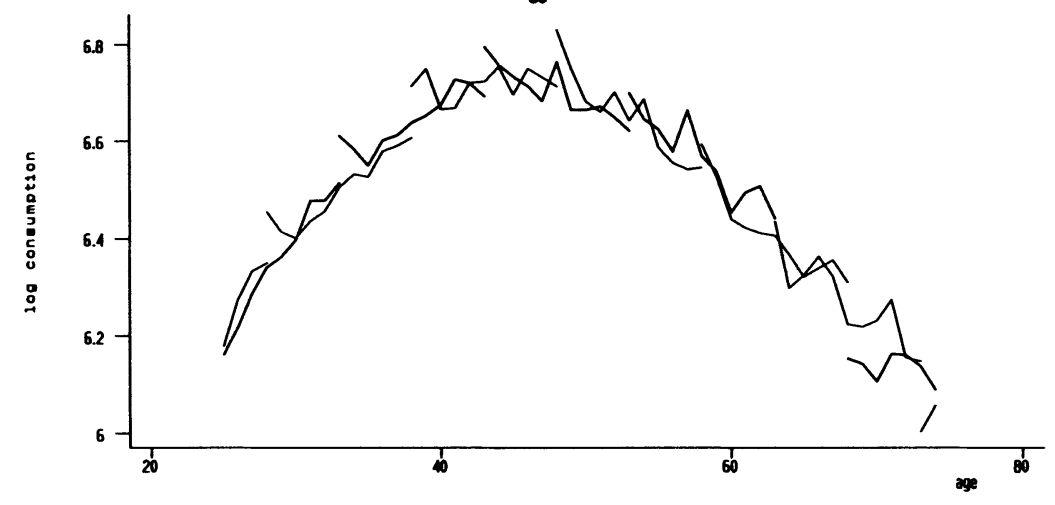

b

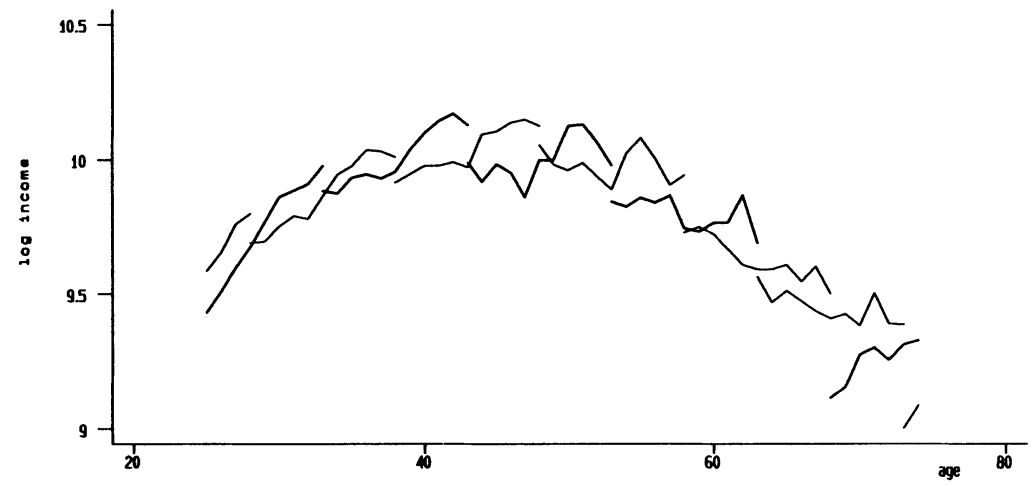

Fig. 1.- $a$, Log of household nondurable consumption. $b$, Log of after-tax household income. 


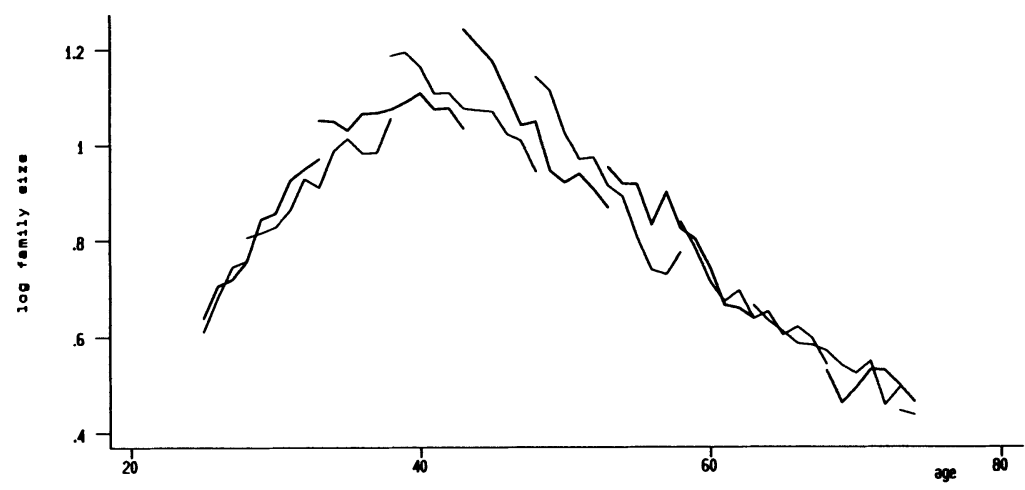

Fig. 2.-Log of family size

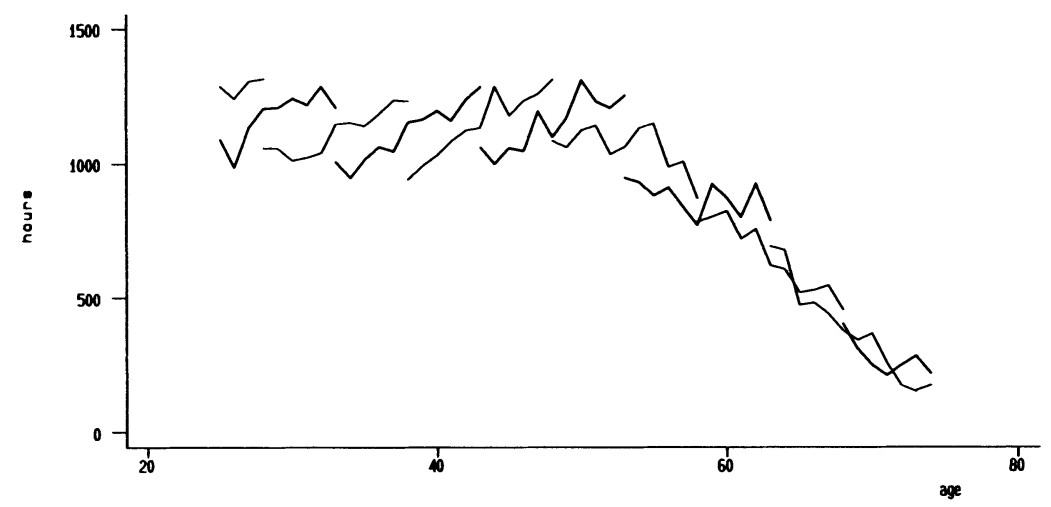

Fig. 3.-Female annual hours of work

wife, but not on positive hours. Several features are worth noticing. First, female labor supply exhibits a substantial amount of variability at both life cycle and business cycle frequencies. Strong cohort effects are also apparent. Second, there is no apparent dip in female hours corresponding to fertility ages. This feature differentiates this profile from similar ones for other countries (such as the United Kingdom) or other time periods.

Several influences affect consumption and are partially detectable in figure 1. We can think of life cycle effects, cohort effects, and business cycle effects. In figure 4 , we try to remove life cycle and cohort effects to isolate time effects. Of course this decomposition is somewhat artificial since the three kinds of effects are not identifiable. By regressing average cohort consumption on cohort dummies and a fifth-degree age polynomial and considering the residuals of such 
a

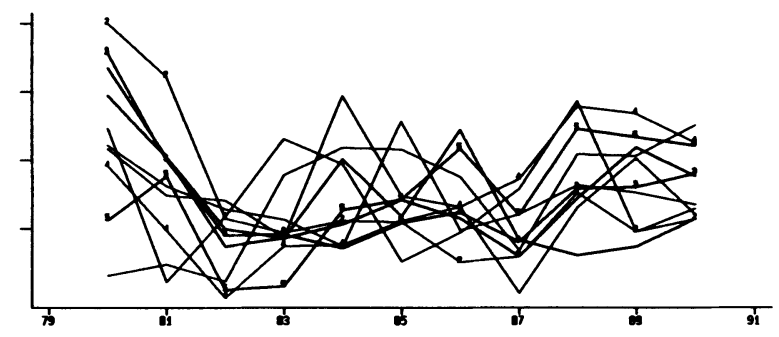

b

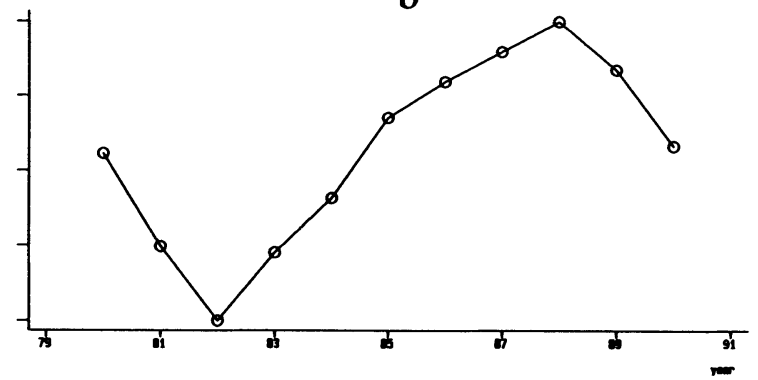

Fig. 4.-Business cycle effects: $a$, cohort data, age and cohort effects removed; $b$, detrended aggregate data.

a regression as time effects, we interpret all trends in consumption as deriving from a combination of cohort and age effects. In figure $4 a$, we plot these residuals against time; in figure $4 b$, we plot detrended aggregate nondurable consumption. Two features are noticeable. First, there is a substantial amount of synchronization across cohorts. The 1981-82 recession is particularly visible. After that, the average residuals seem to rise fairly steadily until the end of the sample. Second, average residuals follow aggregate consumption reasonably well. The correlation coefficient between the average residuals and aggregate detrended consumption is around $.4 .^{7}$

\section{Tuning Up the Basic Model}

A typical Euler equation often used in the empirical literature on consumption is

$$
\Delta \log \left(c_{t+1}^{h}\right)=\text { constant }+\sigma \log \left(1+r_{t+1}\right)+\epsilon_{t+1}^{h},
$$

${ }^{7}$ The presence of measurement error and of definitional differences between the CEX and national accounts consumption should also be kept in mind. 
where $c^{h}$ is individual consumption (expenditure on nondurable goods and services, deflated by a suitable price index), $r$ is the real interest rate, $\sigma$ is the elasticity of intertemporal substitution, and $\epsilon_{t}$ is a residual uncorrelated with all the information available as of time $t-1 .^{8}$ Equation (1) can be derived by log-linearizing the first-order condition from an intertemporally separable optimization problem with isoelastic preferences. If consumers allocate their period $t$ expenditure across commodities in different ways, the price index will be $h$-specific. ${ }^{9}$ Before we even try to fit this equation to the data, a number of simple modifications are necessary. They allow the model to explain some obvious, and yet quantitatively important, features of the data.

The utility derived from a given amount of expenditure obviously depends on, among other things, family composition. In general, it is quite difficult to model properly intrahousehold decisions. Fertility choices are probably endogenous and should be modeled simultaneously with consumption and labor supply behavior. However, it is quite easy to introduce some simple corrections to make the model more realistic. We assume that utility is shifted by a number of demographic variables such as the number of children of various ages, the number of adults, and so forth. Such a framework allows for fairly flexible adult equivalent schemes. The instantaneous utility function for a generic household $h$ that will be used in the empirical application below is

$$
U_{t}^{h}=U\left(C_{t}^{h}\right) \phi\left(Z_{t}^{h}, \theta\right),
$$

where $C_{t}^{h}$ is total family expenditure and $\phi\left(Z_{t}^{h}, \theta\right)$ is a function of various demographic variables. Changes in $\phi$ are equivalent to a timevarying rate of discount. For this reason we shall refer to $\phi$ as the discount factor. If $\phi$ is given by $\phi\left(Z_{t}^{h}, \theta\right)=\exp \left(\theta^{\prime} Z_{t}^{h}\right)$, the term $\theta \Delta Z_{t}^{h}$ enters the log-linearized Euler equation for consumption. In addition to demographic variables, we also consider the presence of seasonal shocks to the discount factor. They will be reflected by the presence of seasonal dummies among the determinants of the discount factor.

An implicit and potentially controversial assumption often used in papers that estimate Euler equations for consumption is separability of the utility function between consumption and leisure. While in this

\footnotetext{
${ }^{8}$ The constant of eq. (1) includes the log of the discount rate and various terms reflecting second and higher moments of the conditional distribution of $\epsilon_{t+1}$. If $\epsilon_{t+1}$ is conditionally lognormal, the constant will include only the variances of consumption growth and the interest rate as well as their covariance.

${ }^{9}$ This is true even if preferences are homothetic, as long as some heterogeneity affects budget shares. In our application we use the Stone price index, which defines $\log (P)$ as the share-weighted sum of the $\log$ of commodity price indices.
} 
paper we do not explicitly model labor supply behavior, we argue that nonseparability between consumption and leisure can be taken into account in a very simple way. Common sense tells us that the level of utility obtained from a given amount of expenditure depends on labor force participation variables: when a member of the household works, he or she will have to bear a number of job-related expenses that will be reflected in total consumption expenditure. These job-related expenses will affect both the intertemporal allocation of expenditure (normally increasing expenditure when leisure is low) and the intratemporal allocation (by making leisure-intensive commodities relatively more expensive). Therefore, we introduce as determinants of the marginal utility of consumption a number of labor supply variables, reflecting both employment status and hours. This strategy allows us to avoid the formal modeling of labor supply, with the complications arising from corner solutions and institutional constraints. This strategy obviously identifies only conditional preferences (see Browning and Meghir 1991). ${ }^{10}$

To summarize, the Euler equation that we estimate is

$$
\Delta \log \left(c_{t+1}^{h}\right)=\text { constant }+\sigma \log \left(1+r_{t+1}\right)+\theta^{\prime} \Delta z_{t+1}^{h}+\epsilon_{t+1}^{h},
$$

where $z$ includes seasonal dummies, demographics, and labor supply variables.

\section{Econometric Issues}

As we said in Section II, the CEX survey is a rotating panel. Rather than employing the (short) panel dimension of the survey, we decided to construct synthetic panels. As in the descriptive analysis of Section II $B$, we define cohort by the year of birth of the household head. Our technique is equivalent to using the interaction of time and group dummies as instruments. We impose an age limit (23-60) and a cell size limit (150) on the cohorts we consider, so that our synthetic panel is not balanced. ${ }^{11}$

There are several advantages in the use of synthetic panel techniques to estimate an Euler equation. First, averaging over individuals belonging to a group should eliminate additive idiosyncratic measure-

10 We also allow for leisure effects in the demand system estimated in Sec. VI, thus producing price deflators that depend on leisure.

${ }^{11}$ See Browning, Deaton, and Irish (1985), Deaton (1985), and Moffitt (1993). We also experimented with groups formed by year of birth and educational attainment. The education groups were the same as those used in the estimation of the demand system. The reason we report results based only on birth year cohorts is that by crossing cohorts and education groups, we are left with very small cells, giving rise to extremely noisy data. The results were extremely imprecise. 
ment error. Second, it is known that if the panel dimension is short, the introduction of household-specific fixed effects gives inconsistent estimates, unless the instruments used are strictly exogenous (see Runkle 1991). Taking cohort averages over long time periods can get around this problem: because we observe groups for the whole sample period (at least potentially), the relevant dimension is the total length of the period covered by the survey, not the length of time each household stays in it. A similar argument can be made about the presence of aggregate shocks. If we think our sample is long enough so that expectational errors are averaged out, the use of more or less standard instrumental variable techniques gives us consistent estimates. This solves the small $T$ problem discussed by Chamberlain (1984) and Hayashi (1987). ${ }^{12}$ Third, we do not need to worry about attrition as much as we would if we were using a long panel. In this respect, as stressed by Moffitt (1993), the use of a time series of cross sections has some advantages relative to the use of panel data. Fourth, even though we work with aggregate data, in that we sum over the individuals belonging to a certain group, we can control the aggregation process directly. In this respect, we can perform interesting exercises to evaluate the extent of aggregation biases.

The use of synthetic panels, however, does not by itself solve some important econometric problems. First, it does not help deal with nonadditive measurement error. We should stress that any form of nonadditive measurement error in the variables of which we take averages induces inconsistent estimates. Second, it does not eliminate concerns about nonrandom attrition. In particular, we have to rely on the assumption that the population from which the sample is drawn is homogeneous over time. This assumption might be violated if, for instance, there is a relationship between mortality and wealth. If this is the case, each cohort would become progressively "richer" as it ages, and therefore we would overestimate the rate of growth of consumption for older cohorts.

The choice of the interval that defines a cohort (in our case 5 years) is arbitrary. On one hand, one wants to have cells that are relatively homogeneous and therefore chooses a narrow interval; on the other hand, it is desirable to have large-size cells, therefore reducing the sampling noise of the resulting pseudo panels. In addition to taking into account this basic trade-off, one wants to define the cohorts so that the resulting panels are able to identify the effects of variables deemed to be important. If one defines a cohort with a very

\footnotetext{
${ }^{12}$ Of course this argument impinges on the assumption that our sample is large enough so that expectational errors are averaged out. While 44 quarterly observations might not be a very large number, it should be stressed that our sample period includes two recessions and a long period of moderate growth.
} 
wide interval, say 40 years, variables such as the demographics would exhibit very little variation and their coefficients would be poorly identified.

Having defined many cohorts, we can estimate a consistently aggregated version of equation (2) for each cohort separately or for all cohorts simultaneously, using appropriate instrumental variable techniques. In what follows, when considering more cohorts, we choose the latter alternative.

Averaging over cells of relatively small size induces measurement error in the levels, which in turn implies an MA(1) structure in the first differences (details are given in the Appendix). Our data do indicate negative first-order autocorrelation, thus suggesting that measurement error is an important issue. As a consequence, the instruments lagged one period are invalid. However, instruments lagged two and more periods yield consistent estimates.

The panel dimension of the CEX implies that temporally adjacent cells do not include completely different households. For instance, households at their first interview in time period $t$ appear also at time $t+1, t+2$, and $t+3$. On the other hand, those at the fourth and last interview at time $t$ also appear at time $t-1, t-2$, and $t-3$. This pattern implies some problems in the construction of instruments yielding consistent estimates that are discussed in detail in the Appendix.

The presence of MA(1) residuals for each cohort is not the only problem with the error structure of equation (1). Because we estimate it for $N$ cohorts simultaneously, the expectational errors for a given time period for different cohorts are likely to be correlated. We allow for contemporaneous correlation among the residuals of different cohorts. We also allow for the presence of arbitrary heteroscedasticity, which is likely to arise because of differences in cell sizes.

The complicated error structure of equation (1) estimated for several cohorts simultaneously has to be taken into account in the construction of an efficient estimator and in the estimation of its standard errors. ${ }^{13}$ Details are provided in the Appendix, where we describe the generalized method of moments (GMM) estimator we use as well as the choice of the instruments.

\section{The Euler Equation for Total Nondurable Consumption}

As stressed in the Introduction, most of the empirical work on intertemporal substitution has used either aggregate data or micro data

${ }^{13}$ A generalized least squares type transformation can generate inconsistent estimates if it involves filtering the system backward (see Hayashi and Sims 1983). 
that contained only limited information on consumption, namely expenditure on food. The use of a time series of cross sections with detailed and exhaustive information on expenditure allows us to estimate the parameters of a flexible specification of preferences and also to replicate the results of other researchers. Not only are the overidentifying restrictions of our specification not rejected, but we can also explain the rejections typically obtained by other researchers. In this section, we address the issue of aggregation across consumers and the necessity to control for the effects of demographics and labor supply on the marginal utility of consumption. We show that the former can explain rejections of the overidentifying restrictions, and the latter accounts for the so-called excess sensitivity of consumption growth to labor income. In Section VI we evaluate the problems connected to the use of food expenditure as a measure of consumption, and in Sections VII and VIII we deal with the aggregation across commodities.

\section{A. Aggregation across Consumers}

Nobody would doubt that actual consumers are heterogeneous. The issue, however, is to establish to what extent heterogeneity affects inferences on the intertemporal optimization model based on aggregate data. ${ }^{14}$ Using a long time series of U.K. cross sections, Attanasio and Weber (1993) have shown that aggregation bias can explain the rejection of the overidentifying restrictions implied by the model. The Euler equation derived from isoelastic preferences implies a nonlinear relationship between consumption and the interest rate at the individual level. Using aggregate data to estimate and test such a relationship is equivalent to taking the log of the mean rather than the mean of the log. One of the advantages of working with a time series of cross sections is that one can control the aggregation process directly: we can aggregate any known nonlinear function of the individual data and evaluate the effects of improper aggregation.

Equation (2) can be aggregated across consumers to obtain a similar equation for aggregated data:

${ }^{14}$ The use of a representative consumer can be justified, theoretically, if one assumes the existence of perfect insurance markets. Attanasio and Davis (1994) show overwhelming evidence against this hypothesis. Furthermore, even in the presence of complete markets, the nonlinearity issue would still be relevant, unless we impose special preferences on the individual agents. In a recent paper, Mace (1991) reports results obtained using the CEX that could be interpreted in favor of the perfect insurance hypothesis. However, they could simply reflect the presence of measurement error. Cochrane (1991), using PSID data, finds evidence against the hypothesis. 


$$
\begin{aligned}
\frac{1}{H} \sum_{h} \Delta \log \left(c_{t+1}^{h}\right)= & \text { constant }+\sigma \log \left(1+r_{t+1}\right) \\
& +\theta^{\prime} \frac{1}{H} \sum^{h} \Delta z_{t+1}^{h}+\frac{1}{H} \sum^{h} \epsilon_{t+1}^{h} .
\end{aligned}
$$

In the absence of individual data, researchers have estimated

$$
\begin{aligned}
\Delta \log \frac{1}{H} \sum_{h} c_{t+1}^{h}= & \text { constant }+\tilde{\boldsymbol{\sigma}} \log \left(1+r_{t+1}\right) \\
& +\tilde{\theta}^{\prime} \Delta \log \left(\frac{1}{H} \sum^{h} z_{t+1}^{h}\right)+v_{t+1} .
\end{aligned}
$$

In table 2 , we present estimates of equations $\left(1^{\prime}\right)$ and $\left(1^{\prime \prime}\right)$. We did not search for a satisfactory specification: the exercise is meant only to show the effects of incorrect aggregation.

Row 1 in table 2 reports estimates for the correctly aggregated nondurable consumption measure. Row 2 reports estimates for the incorrectly aggregated model (we have taken the logarithm of the arithmetic mean, as is normally done on aggregate time-series data). ${ }^{15}$ Four seasonal dummies (S1-S4) are introduced to take into account seasonality in preferences. Changes in family size are also used as an explanatory variable to take into account that, in aggregate studies, consumption is usually expressed in per capita terms. ${ }^{16}$ The real interest rate is the final explanatory variable and is treated as endogenous in estimation. The GMM estimator used is the same as that used for the subsequent tables and is described in detail in the Appendix. The instrument set includes the second and fourth lags of consumption growth, the second lag of inflation and the interest rate, the seasonal dummies, and the change in log family size. The sample size is 39 because we aggregate the whole sample instead of considering separate cohorts.

The key difference between the two columns occurs in the Sargan test for overidentifying restrictions. The test statistic (defined in the Appendix) is sensitive to the instrument set used in estimation: to enhance its power we have chosen a parsimonious list of overidentifying instruments on the basis of first-stage regressions. With the chosen instruments, we find that the test rejects the null in column 2 but fails to reject it in column 1 . The test result for the specification that

\footnotetext{
${ }^{15}$ We have used CEX-provided population weights to enhance comparability with published national accounts data, but similar results obtain when unweighted averages are taken instead.

${ }^{16}$ If the family size variable is omitted or its coefficient constrained to unity, the results are similar.
} 
TABLE 2

Estimates Based on Aggregate CEX Data (Weighted)

$$
\frac{1}{H} \sum_{h} \Delta \log \left(c_{t+1}^{h}\right)=\text { intercept }+\tilde{\sigma} r_{t+1}+\theta \frac{1}{H} \sum^{h} \Delta \log (\text { famsize })_{t+1}^{h}+v_{t+1}
$$

\begin{tabular}{lcc}
$\theta$ & $\sigma$ & $\begin{array}{c}\text { Sargan Criterion } \\
(p-\text { Value }) \\
(1)\end{array}$ \\
\hline .855 & $(2)$ & 2.02 \\
$(.256)$ & .214 & $(.569)$ \\
\hline
\end{tabular}

$$
\Delta \log \frac{1}{H} \sum_{h} c_{t+1}^{h}=\text { intercept }+\tilde{\sigma} r_{t+1}+\tilde{\theta} \Delta \log \left(\frac{1}{H} \sum^{h} \text { famsize }_{t+1}^{h}\right)+\tilde{v}_{t+1}
$$

\section{$\tilde{\theta}$}

(1)

\section{.474}

(.246)
(2)
Sargan Criterion

( $p$-Value)

\subsection{2}

$(.038)$

Note.-MA(1)-consistent standard errors are in parentheses. The intercept in each equation is season-specific. Instruments used are the second and fourth lags of consumption growth, the second lag of inflation, and the interest rate, plus the following exogenous explanatory variables: S1-S4 and $\Delta \log ($ famsize). The Sargan criterion is a $x^{2}$ test of the overidentifying restriction with three degrees of freedom.

uses arithmetic averages is in line with the evidence from aggregate data, where overidentifying restrictions are typically rejected (e.g., Hansen and Singleton 1982). ${ }^{17}$

Incorrect aggregation is a plausible explanation of this result. The difference between the geometric and arithmetic average is an index of inequality, which, as shown by Attanasio and Weber (1993), is serially correlated and covaries with business cycle indicators. Because the instruments include lags of the endogenous variables, they are likely to be correlated with it.

\section{B. Demographics, Labor Supply, and Excess Sensitivity}

Following Flavin (1981), several papers have used aggregate and individual data to study the relationship between expected consumption growth and expected income growth. The papers by Campbell and Mankiw (1989) on the macro side and by Hall and Mishkin (1982)

${ }^{17}$ When we employ the much larger instrument set used to produce the estimates from a larger sample reported in the following tables, the Sargan test fails to reject the null for both specifications. However, the misspecification of the equation that uses arithmetic means is detected by an autocorrelation test and by some evidence of excess sensitivity of consumption to income. When we add income growth to the specification in table 2, we find some weak evidence of excess sensitivity, particularly if we fail to control for family size. 
and Zeldes (1989) on the micro side are only a few examples of the many studies that performed "excess sensitivity" tests. The idea is that under a simple version of the life cycle model, there should be no relationship between these two variables, since consumers with a concave utility function should smooth expected income fluctuations. However, besides the aggregation problems discussed above, these studies neglect the possibility that the marginal utility of consumption is affected by demographic or labor supply variables.

In column 1 of table 3 , we report the results obtained estimating equation (2) with the addition of the rate of growth in labor income and, as a sole control for demographics, the log change in family size. The estimates are obtained using the GMM technique described in the Appendix for several cohorts simultaneously. The instruments, including several lags of the variables included as well as seasonals, age, and age squared, are listed in the table note. Below the variable names we report the $R^{2}$ 's of the first step regression of each of the variables on the instruments (for the longer sample). ${ }^{18}$

The coefficient on the interest rate is almost 0.4 , but is imprecisely estimated. The coefficient on labor income growth, however, is 0.25 with a $t$-statistic above four. Excess sensitivity is enhanced if we eliminate the family size variable. The Sargan test of overidentifying restrictions does not reject the null. In column 4 the same equation is estimated for a shorter sample that excludes data for 1980 and 1981, which were collected with a slightly different methodology (see the discussion in Sec. VI). These results are qualitatively similar to those of column 1 and are consistent with most of the results in the literature, which have been interpreted as an indication of excess sensitivity of consumption to income.

In column 2 (and 5 for the shorter sample), we add to the specification in column 1 several variables that are meant to capture the effects of changing family composition and labor supply on the discount factor $\phi(\cdot)$. After trying several specifications, we settled on the one reported. The main conclusions we draw are robust to the inclusion of additional demographic variables or to the exclusion of some of the less significant ones.

In the specification reported, the discount factor $\phi(\cdot)$ is assumed to depend on seasonal dummies, on the log of family size, on the number of children between the ages of 0 and 15, on a dummy that equals unity if the wife works full-time, on the log of annual hours of leisure enjoyed by the wife (computed as 5,000 minus the number of hours of work), and on a dummy for single individuals. Other variables that

\footnotetext{
${ }^{18} \mathrm{We}$ also tried the rate of growth in total after-tax family income and different instrument sets, and we obtained comparable results.
} 
TABLE 3

Euler EQUATION for Total Consumption ExPENDiture (Using Stone Price Index to Deflate Total Nondurable Expenditure)

\begin{tabular}{|c|c|c|c|c|c|c|}
\hline & \multicolumn{3}{|c|}{$\begin{array}{c}1981: 3-1990: 4 \\
\text { (Cohorts } 1-8 ; N=288)\end{array}$} & \multicolumn{3}{|c|}{$\begin{array}{c}1982: 3-1990: 4 \\
\text { (Cohorts } 1-8 ; N=256)\end{array}$} \\
\hline & (1) & (2) & (3) & (4) & (5) & (6) \\
\hline Real interest rate & .392 & .341 & .149 & .386 & .480 & .331 \\
\hline .51 & $(.280)$ & $(.276)$ & $(.347)$ & $(.212)$ & $(.282)$ & $(.316)$ \\
\hline$\Delta \log ($ famsize $)$ & .365 & 1.172 & .948 & .534 & 1.539 & 1.413 \\
\hline & $(.186)$ & (.399) & $(.479)$ & $(.178)$ & $(.383)$ & $(.417)$ \\
\hline$\Delta$ children & & -.539 & -.453 & & -.617 & -.558 \\
\hline & & $(.169)$ & $(.200)$ & & $(.186)$ & $(.192)$ \\
\hline$\Delta w w$ & & -1.551 & -1.560 & & -1.808 & -1.826 \\
\hline .12 & & $(.666)$ & $(.639)$ & & $(.665)$ & $(.649)$ \\
\hline$\Delta \ln (w l)$ & & -2.578 & -2.486 & & -3.207 & -3.011 \\
\hline .07 & & $(.835)$ & $(1.046)$ & & $(1.185)$ & (1.144) \\
\hline $\begin{array}{l}\Delta \text { single } \\
.07\end{array}$ & & $\begin{array}{r}-2.239 \\
(.912)\end{array}$ & -2.157 & & $\begin{array}{c}-2.744 \\
(898)\end{array}$ & -2.567 \\
\hline$\Delta \log ($ labor income $)$ & .247 & & $\begin{array}{c}(.900) \\
.100\end{array}$ & .200 & & $\begin{array}{l}(.987) \\
.094\end{array}$ \\
\hline & $(.058)$ & & (.103) & $(.060)$ & & $(.089)$ \\
\hline Sargan criterion & 24.85 & 11.66 & 12.34 & 30.13 & 12.11 & 13.06 \\
\hline$(p$-value $)$ & $(.36)$ & $(.92)$ & $(.87)$ & $(.15)$ & $(.91)$ & $(.84)$ \\
\hline
\end{tabular}

NoTE.-Asymptotic standard errors are in parentheses. All specifications include a constant and three seasonal dummies. The instrument set is the same across columns and includes the second to fourth lags of consumption growth, inflation, nominal interest rates, and labor income growth; the second and third lags of all the other variables listed; the second and third lags of the number of earners; three seasonal dummies; age; age squared; and a constant. The numbers under the variable names are the $R^{2}$ 's of the first step regression on the 1981:3-1990:4 sample. $w w$ is the dummy for the wife working full-time, $\ln (w l)$ is the $\log$ of the wife's annual hours of leisure, single is the dummy for single consumers, and children is the household members between the ages of 0 and 15 .

were considered during the specification search include the number of children of various ages, a dummy for part-time working wife, and the number of earners. ${ }^{19}$ We also considered variables such as the number of vehicles and dummies for homeownership.

All variables in the equation, with the exception of seasonals, are instrumented. There are two reasons for using this procedure. First, some of the variables considered are choice variables determined simultaneously with consumption. Second, given the size of our sample, they all are subject to measurement error. As argued above, the presence of measurement error and therefore of $\mathrm{MA}(1)$ residuals makes lag 1 instruments invalid. The instruments used were second, third, and fourth lags of interest rates, consumption, and income growth and inflation; the second and third lags of all the variables

19 The cohort average of a dummy variable (such as that for working wives) measures the proportion of households, within a particular quarter-cohort cell, that meet a specified condition. 
considered in the discount factor; and the number of earners, age, age squared, a constant, and three seasonal dummies.

The point estimate of the coefficient on income is more than halved and that of its standard error increased, so that the coefficient is not statistically different from zero. In column 2 (but not in col. 5), the point estimate of the coefficient on the interest rate is also greatly reduced. In both columns 2 and 5, the Sargan test fails to reject the overidentifying restrictions.

In columns 3 and 6 , we report our favorite specification, obtained eliminating from columns 2 and 5 the rate of growth in income. The coefficient on the interest rate, which in the present specification is equal to the elasticity of intertemporal substitution, is estimated at 0.34 in the long sample and at 0.48 in the short one, but without much precision. Once again, the Sargan test does not reject the null.

\section{Interpretation}

The results discussed in this section show that the rejections of the life cycle-permanent income model typically obtained in the empirical literature on consumption using aggregate time-series data can be explained by aggregation problems and by the failure to control for important factors such as the effect that demographics and labor supply variables have on utility. In table 2 , we have shown that nonlinearities can lead to rejections of the overidentifying restrictions. In table 3, we have shown that excess sensitivity disappears once some demographic and labor supply variables are allowed to affect the discount factor. It should be stressed that this result cannot be explained by large measurement error in our measure of labor income or by the inability of the instruments to capture its variability: the $R^{2}$ of the first-stage regression for income is above .2, higher than that for the demographic and labor supply variables, and we do obtain excess sensitivity when we do not control for demographic and labor supply variables. Nor can the result be explained by excessive noise induced by a large number of insignificant variables: the point estimate of the coefficient on income is considerably reduced by the introduction of the various controls. ${ }^{20}$

${ }^{20}$ Following Zeldes (1989) and Runkle (1991), much of the consumption literature that used micro data has tested for excess sensitivity by dividing the sample on the basis of income or wealth. The idea is that wealthier individuals are less likely to exhibit excess sensitivity. Here we do not pursue this line of research for several reasons. First, we do not have a true panel but work with a pseudo panel. It is therefore impossible to split the sample on the basis of variables that change over time, such as income and wealth. Furthermore, we have shown that in our data, one observes excess sensitivity when one fails to control properly for demographics and does not when such controls are introduced. When we performed the same exercise separately on younger cohorts (and therefore more likely to be liquidity constrained), we obtained the same result. 
As is evident from the estimates, some of the demographic variables are quite important. Attanasio et al. (1995) plot the life cycle profiles for the discount factors implied by a specification similar to the present one and estimated on the same data set. They show that, when used to solve and simulate a life cycle model, these estimated discount factors are able to generate not only the hump-shaped profile that characterizes life cycle consumption but also the differences across education groups. ${ }^{21}$

The specification presented in columns 3 and 6 of table 3 is theoretically appealing and does not present signs of excess sensitivity. Furthermore, the overidentifying restrictions are not rejected. The equation, however, could be misspecified if intertemporal allocation cannot be described by using a single price index. In Sections VII and VIII we address the issue of aggregation across commodities. But first we look at the consequences of proxying consumption with the expenditure on food.

\section{Food Consumption}

Most of the U.S. literature on the life cycle model based on micro data has used the PSID, which contains only information on food consumption. ${ }^{22}$ This is a very serious limitation. The assumption necessary to justify the use of food to study the intertemporal allocation of consumption is that utility is separable between food and other consumption goods. All available studies of demand systems strongly reject such a hypothesis. Furthermore, if the aim of the exercise is to estimate behavioral parameters, such as the elasticity of intertemporal substitution, it is questionable whether those obtained using food consumption are indicative of the substitutability over time of total consumption. Finally, the isoelastic specification often assumed in empirical studies is particularly ill suited for food, which is a necessity (i.e., the budget share of food falls as the budget rises).

In table 4, we report the results obtained estimating equation (2) with consumption defined as expenditure on food. The specification of the equation is similar to that estimated by several authors, such as Zeldes (1989), Runkle (1991), and Keane and Runkle (1992). In column 1 the rate of growth in food consumption at the cohort level is related to the real interest rate (obtained subtracting the rate of growth in food prices from the nominal rate) and to other control variables such as seasonal dummies and the log of family size. Instru-

${ }^{21}$ Even though the taste parameters are assumed to be the same across education groups, the discount factors (and therefore the implied consumption profiles) will differ because the forcing variables-demographics and labor supply-differ across education groups.

${ }^{22}$ A notable exception is the paper by Lusardi (1992), who also used the CEX. 
TABLE 4

Estimates Based on Food Consumption $(N=288)$

\begin{tabular}{lcccc}
\hline \hline & $(1)$ & $(2)$ & $(3)$ & $(4)$ \\
\hline$\Delta \log ($ famsize) & .459 & .271 & .292 & .383 \\
Real interest rate & $(.142)$ & $(.165)$ & $(.158)$ & $(.160)$ \\
& -.733 & -.862 & -.551 & -.369 \\
$\Delta \log$ (labor income) & $(.253)$ & $(.277)$ & $(.363)$ & $(.323)$ \\
$\Delta \log$ (other nondurables) & & .177 & .101 & \\
Sargan criterion & & $(.067)$ & $(.089)$ & .189 \\
$(p$-value) & 12.1 & & .170 & $(.088)$ \\
& $(.88)$ & $(.86)$ & 10.2 & 10.2 \\
& & & $(.89)$ & $(.95)$ \\
\hline
\end{tabular}

NoTE.-MA(1)-consistent standard errors are in parentheses. Instruments used are second, third, and fourth lags of food and other durable consumption growth, income growth, inflation, and the nominal interest rate; the second lag of family size growth; and the following exogenous variables: S1-S4, age, and age squared. The Sargan criterion is a $\chi^{2}$ test of the overidentifying restriction.

ments used include second to the fourth lags of interest and inflation rates; second to the fourth lags of income, food, and other nondurable consumption growth; and a polynomial in age and lagged demographics. The results are not greatly affected by the introduction of other demographic variables or by a change in the instruments.

The estimate of the coefficient on the interest rate is negative and statistically different from zero. The Sargan criterion does not indicate a rejection of the overidentifying restrictions.

In column 2, we add to the specification the rate of growth in labor income. The coefficient of this variable is estimated at 0.18 with a standard error of 0.07 . Its introduction does not considerably affect the remaining coefficients or the test of overidentifying restrictions.

In column 3, we add to the specification in column 2 the rate of growth of consumption of other nondurable commodities. The coefficient on this additional variable is estimated at 0.17 with a standard error of 0.10 , which makes it marginally different from zero. The point estimate of the coefficient on income is greatly reduced and is no longer statistically different from zero. The coefficient on the interest rate is still negative and (marginally) different from zero.

In column 4, we remove the rate of growth of income. The coefficient on other nondurables is now strongly significant. The coefficient on the interest rate, however, is still negative but not statistically different from zero. ${ }^{23}$

${ }^{23}$ The food figures for 1980 and 1981 might be of particularly low quality. Because of this we reestimated the columns in table 4 over the period 1982:3-1990:4. The results, available on request, are very similar to those in table 3. 
We interpret the evidence in table 3 as indicating that the nonseparability between food and other nondurables is a potentially important problem.

The estimates of the elasticity of food consumption growth to the real interest rate presented here differ from those available in the literature (see, e.g., Zeldes 1989; Runkle 1991; Keane and Runkle 1992). These differences could be due to a variety of factors including, for instance, the use of a different survey in which the timing of food expenditure is better determined. An important difference occurs in the econometric methodology. The use of synthetic panels (rather than a short panel at the individual level) affords important gains in the time dimension of the sample. Given that the error term has an expectational component, this is a matter of great importance.

\section{The Allocation of Consumer Expenditure over Time with Multiple Commodities}

Food is a necessity and, as we have shown in the previous section, is unlikely to be separable from other nondurables. Therefore, food expenditure is inadequate to study the intertemporal allocation of consumption. On the other hand, even when data on total nondurable expenditure are available, it is not obvious that its intertemporal allocation could be described, in the presence of large changes in relative prices, by a single price index. It might be necessary to model the intratemporal and the intertemporal allocation of consumption simultaneously.

In this respect, several modeling strategies are available. One could formulate within-period utility as a function of several commodities and consider the Euler equation for each of them. The main problem here is to find a flexible direct utility function that nests the isoelastic case (and for which integrability conditions can be imposed by setting data-independent restrictions on the parameter space). Alternatively, one could consider flexible specifications for marginal utilities and estimate the Euler equations from them. In this case, however, quasi concavity of the implied utility function might be hard to impose. Finally, one can choose to work with an indirect utility function that captures both nonhomotheticity and nonseparability.

We adopt this last strategy. While most of the theoretical results used in the analysis are well known at least since Gorman (1959), the specification of preferences we present is relatively new. We introduce an empirically tractable way to consider the intertemporal allocation problem when within-period utility depends on several commodities. Our specification relaxes the assumption of homotheticity and therefore does not allow the characterization of intertemporal 
allocation by means of a single price index. The homothetic case, however, is nested as a special case and can be obtained with simple restrictions on the parameters we estimate. Our specification of preferences is similar to that used by Blundell, Browning, and Meghir (1994) but presents the key advantage of producing an Euler equation for consumption that nests equation (1) when preferences are homothetic.

When one considers several commodities, one can think of $c_{t}$ as total expenditure deflated by an appropriate price index. However, as Gorman (1959) proved, only under very stringent conditions can the intertemporal optimization problem be determined on the basis of a single price index.

One can interpret the standard objective function of the dynamic optimization problem as the utility index of a consumer who breaks her optimization problems into two steps: in the first step, she decides how much expenditure $X$ to allocate to each time period. In the second step, she allocates $X$ to different goods $\left(q_{1}, \ldots, q_{N}\right)$, given their relative prices and $X$ (some goods will be luxuries, some necessities). Suppose that the second step produces demand equations of the almost-ideal type (see Deaton and Muellbauer 1980):

$$
\frac{q_{i t} p_{i t}}{X_{t}}=\alpha_{i}=\sum_{j} \gamma_{i j} \ln \left(p_{j t}\right)+\beta_{i}\left[\ln \left(X_{t}\right)-\ln a\left(p_{t}\right)\right],
$$

where the $p$ 's are individual prices ( $\mathbf{p}$ is the corresponding price vector); $\alpha, \gamma$, and $\beta$ 's are preference parameters (which may be functions of demographic characteristics, employment, etc., as in Blundell, Pashardes, and Weber [1993]); and

$$
\ln \left[a\left(p_{t}\right)\right]=a+\Sigma \alpha_{i} \ln \left(p_{i t}\right)+.5 \sum_{i} \sum_{j} \gamma_{i j}^{*} \ln \left(p_{i t}\right) \ln \left(p_{j t}\right)
$$

If all the $\beta$ 's are zero, preferences are homothetic, and the indirect utility function for period $t$ consumption is

$$
V=F\left[\frac{X_{t}}{a\left(p_{t}\right)}\right]=F\left[c_{t}\right],
$$

where $F[\cdot]$ is a monotonic transformation (which cannot be identified from the demand system alone and determines the intertemporal allocation). Equation (4) implicitly defines $c_{t}$ as nominal expenditure $X_{t}$ deflated by the linear homogeneous price index $a\left(p_{t}\right)$.

On the other hand, if the $\beta$ 's are nonzero, violating homotheticity, the indirect utility function becomes

$$
V^{*}=F\left[\left[\frac{X_{t}}{a\left(p_{t}\right)}\right]^{1 / b\left(p_{t}\right)}\right],
$$


where $b\left(p_{t}\right)=\Pi_{i} p_{i t}^{\beta_{i}}$, that is, a zero-degree homogeneous price index (adding up implies $\Sigma \beta_{i}=0$ ). This second price index takes into account the different impact price changes have on utility according to the type of good they refer to $\left(\beta_{i}>0\right.$ for luxury goods, $\beta_{i}<0$ for necessities).

Neglecting the existence of this second price index may lead to spurious inferences. Equation (1) will suffer from omitted variable bias because no account is taken of changes in $b\left(p_{t}\right)$ over time. This problem is particularly severe if over the sample period analyzed there are large changes in relative prices across luxuries and necessities (e.g., if luxuries become relatively more expensive in booms and cheaper during recessions).

If the maximand of the dynamic optimization problem is

$$
U=\sum_{t} \frac{1}{1-(1 / \sigma)}\left\{\left[\frac{X_{t}}{a\left(p_{t}\right)}\right]^{1 / b\left(p_{t}\right)}\right\}^{1-(1 / \sigma)} \frac{e^{\theta z_{t}}}{(1+\delta)^{t}},
$$

the Euler equation (1) becomes (after some manipulations)

$$
\begin{aligned}
\Delta \frac{\ln \left(c_{t+1}\right)}{b\left(p_{t+1}\right)}=\psi+\sigma\left\{r_{t+1}^{*}\right. & -\Delta \ln b\left(p_{t+1}\right) \\
& \left.-\Delta\left[\ln \left(c_{t+1}\right)-\frac{\ln \left(c_{t+1}\right)}{b\left(p_{t+1}\right)}\right]\right\}+\theta \Delta z_{t+1} .
\end{aligned}
$$

This expression simplifies to equation (2) when all the $\beta$ 's are zero (in which case $b(p)=1)^{24}$

When the $\beta$ 's are not zero, the second price index rescales the dependent variable and it affects the definition of the real interest rate. The real interest rate (normally obtained by subtracting from the nominal rate the rate of inflation in $a(p))$ is further deflated by the growth rate of the second price index, $b(p)$, and by a correction term, which is the difference between consumption growth as normally defined and the dependent variable. This specification is easy to estimate, particularly if the $\beta$ 's are known in advance: this is the case if we estimate Engel curves separately in each year. ${ }^{25}$

${ }^{24}$ Blundell, Browning, and Meghir (1994) estimate an Euler equation similar to (7), but with further nonlinearities. Their analysis is different in two respects. On the one hand, their demand system is consistent with a wider pattern of Engel curves (and nests the almost-ideal case from which we start). This is useful for welfare analysis, as stressed by Banks, Blundell, and Preston (1994). On the other hand, their monotonic transformation in $V^{*}$ takes as argument a nonlinear function in $X$. This second feature implies that even in the homothetic case their Euler equation does not simplify to eq. (1). In the almost-ideal case, e.g., their Euler equation involves taking the logarithm of $\log$ (consumption), a particularly unappealing data transformation, which rules out very low but theory-consistent consumption levels.

${ }^{25}$ Demographic variables will enter eq. (7) in two ways: directly, as taste shifters affecting the discount factor $\phi$ (defined in Sec. III), and indirectly, via the two price indices, $a(p)$ and $b(p)$. 
In equation (7), $\sigma$ is no longer the elasticity of intertemporal substitution (EIS): its multigood definition is EIS $=(-) V_{x}^{*} / X V_{x x}^{*}$ (Browning 1987), where an $x$ subscript denotes the partial derivative with respect to $X$. This implies

$$
\operatorname{EIS}=-\frac{\sigma b(p)}{1+\sigma[b(p)-1]}
$$

\section{Estimation Results for Nonhomothetic Preferences}

If some goods are necessities and other goods are luxuries, and their relative prices change, then at least two price indices are needed to deflate nominal expenditure. Failing to model the features of preferences that prevent the consideration of a single price index (nonhomotheticity) introduces an omitted variable problem that can induce serious biases.

In figure 5, we plot the relative price of food and other nondurables over the 1980 s, which presents a substantial amount of variability. In particular, around 1986 the relative price of food and other nondurables exhibits a substantial shock. This is due to the decline in the prices of oil products, which are included in nondurables.

One can observe changes in consumption shares that correspond to these changes in relative prices. In figure 6 , we plot the average share of food in nondurable expenditure over the 1980s. The graph exhibits a substantial drop in 1982 followed by a more gentle decline up until 1985, when the share of food starts to increase again. Part of the dramatic drop of 1982 is probably explained by data problems. ${ }^{26}$ For this reason, we report results for both the whole sample and a subsample that excludes the first two years.

In the empirical implementation of the model presented in subsection $A$, we proceed in two steps. We first estimate a flexible demand system that satisfies integrability conditions. The results obtained in this step are then used to construct the price indices necessary to characterize intertemporal allocation. We then estimate the corresponding Euler equation.

${ }^{26}$ The BLS runs a separate sample, based on diaries rather than interviews, to collect information on expenditure on food and other frequently purchased items. In 1980 and 1981 (but not in later years), average food consumption was substantially higher in the interview survey than in the more reliable diary survey. A direct comparison with the share of food that can be computed from National Income and Product Accounts figures is not feasible because of definitional differences in some of the items included in nondurable consumption. The aggregate food share shows a constant and gentle decline that slows down around 1985. 


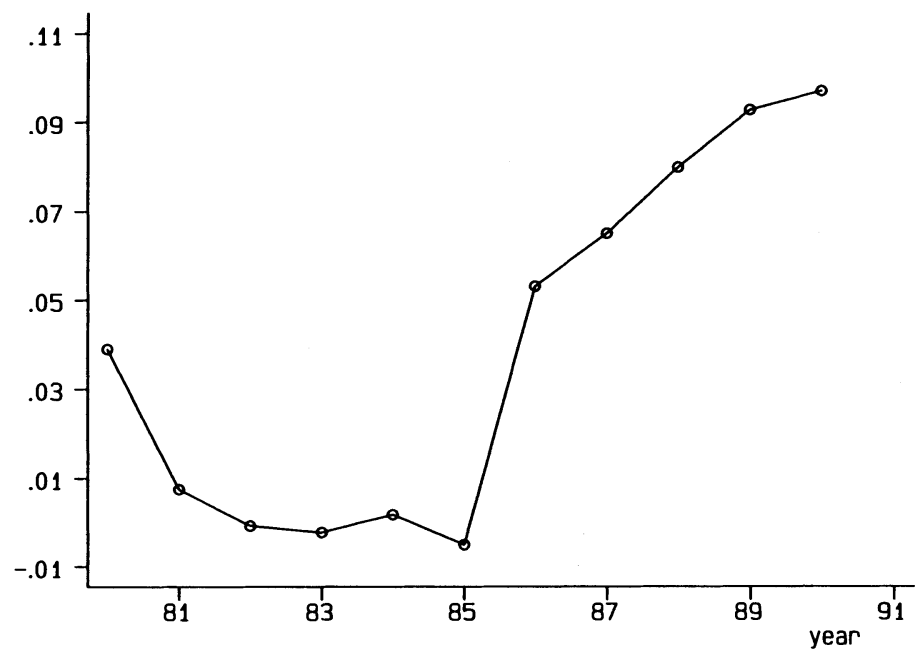

Fig. 5.-Relative price of food

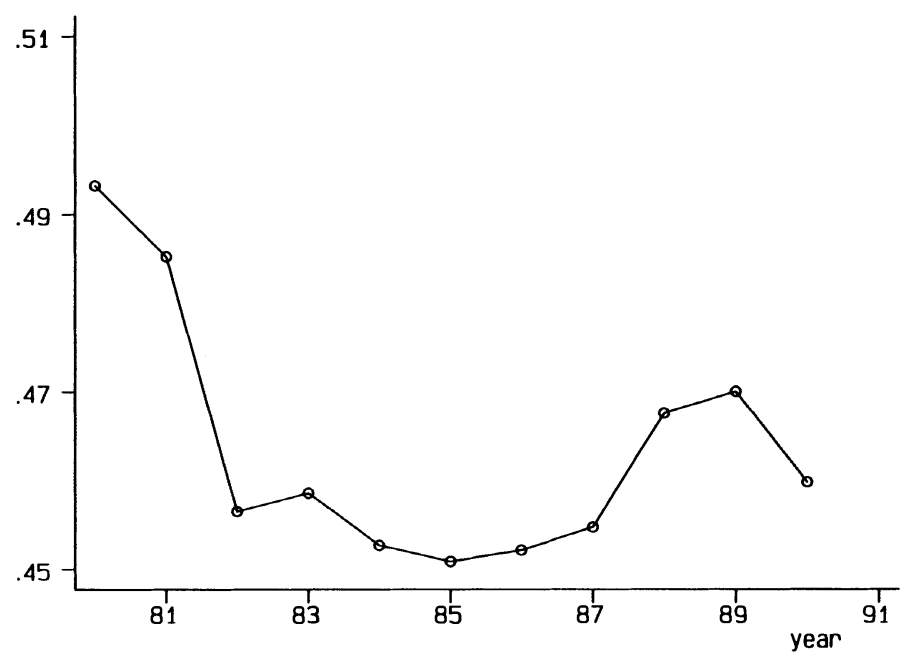

FIG. 6.-Share of food

\section{A. Demand System}

We split total nondurable expenditure on food and all other nondurable goods and services. This split, while arbitrary, has the advantage of grouping (potential) necessities separately from (potential) luxuries and of defining commodities for which zero expenditures are not reported.

The two-commodity demand system we estimate is of the almost- 
ideal type (see eq. [3] above): the dependent variables are the budget shares of food and of other nondurables, and the explanatory variables are their prices and total nondurable expenditure (the budget), deflated by a linearly homogeneous price index, $a(p)$. Because the budget shares add up to one, an equation is redundant and we estimate and report just the food equation without loss of generality.

In principle, all preference parameters $(\alpha, \gamma$, and $\beta$ 's) could vary across households. We restrict their variation in the following ways: we assume $\gamma$ 's and $\beta$ 's to be constant within educational groups and the $\alpha$ 's to depend on a few demographic and labor market variables. We therefore estimate separate budget share equations for food for each of four groups formed on the basis of the educational attainment of the household head: high school dropouts, high school graduates, college dropouts, and college graduates. For each educational group, the $\alpha$ parameter (which affects both the intercept and the $a(p)$ index deflating nominal expenditure) is allowed to depend on some deterministic variables (seasonal dummies and a zero-one indicator for the 1980-81 wave of interviews), some demographic indicators (age of the head, single adult dummy, total number of family members, and the number of children), and a few zero-one labor market variables (head unemployed, second adult works full-time, second adult works part-time, and log of female leisure). All these variables significantly affect the budget share of food for at least one educational group, but none of the nondeterministic variables plays a key role in determining the $\beta$ parameter, that is, the degree of nonhomotheticity.

In order to avoid the measurement error problems (discussed in Blundell, Pashardes, and Weber [1993]) typical of household-level data, we have estimated consistently aggregated budget share equations at the cohort level. This is equivalent to treating all explanatory variables as endogenous and using year-quarter-cohort dummies as instruments. We concentrated on 10 year-of-birth cohorts and therefore have 430 observations for each equation. In estimation we impose all theory restrictions (homogeneity is never rejected; symmetry is marginally rejected in two of the four equations).

In table 5 , we report parameter estimates for $\beta$ and descriptive statistics of some key elasticities by educational group. Two things are worth noticing. First, the estimates confirm, not surprisingly, that food is a necessity. Second, the budget elasticities of food expenditure decline monotonically with educational attainment, ranging from 0.88 for high school dropouts to 0.61 for college graduates. Price elasticity is lowest for college graduates and (in absolute value) considerably less than unity.

These results imply that one needs at least two price indices to describe intertemporal allocation over time. This follows from the 
TABLE 5

Elasticities Derived from the Demand System

\begin{tabular}{lccc}
\hline & $\beta$ & $\begin{array}{c}\text { Budget Elasticity } \\
\text { at the Mean }\end{array}$ & $\begin{array}{c}\text { Uncompensated Price } \\
\text { Elasticity at the Mean }\end{array}$ \\
\hline High school dropouts & -.064 & .877 & -.577 \\
& $(.016)$ & $(.03)$ & $(.06)$ \\
High school graduates & -.074 & .841 & -.513 \\
& $(.016)$ & $(.035)$ & $(.06)$ \\
College dropouts & -.099 & .781 & -.580 \\
& $(.011)$ & $(.025)$ & $(.06)$ \\
College graduates & -.166 & .616 & -.438 \\
& $(.011)$ & $(.027)$ & $(.08)$ \\
\hline
\end{tabular}

NoTE.-Standard errors are in parentheses. The standard errors of the elasticities at the mean are computed using the delta method.

fact that food consumption is a necessity and from the fact that over the sample period the relative price of food and other nondurables changed dramatically.

\section{B. Euler Equations}

In table 6, we report the results obtained estimating the Euler equation (7). They incorporate the estimates of the demand system discussed above through the price indices. ${ }^{27}$ For comparison, the specifications reported are equivalent to those in columns 3 and 6 of table 3. The estimation method and the instruments used are also the same.

The coefficient on the interest rate is no longer equal to the EIS, but it is related to it by the expression in equation (8). In practice, however, the estimated parameters of our demand system and the behavior of relative prices imply a very small variability of $b(p)$, which, in the sample, ranges from 0.99 to 1.01 . Therefore, for all practical purposes, we can consider the estimated coefficients on the real interest rate as an estimate of the EIS. This coefficient is estimated at 0.56 (s.e. $=0.22)$ for the whole sample and at $0.67($ s.e. $=0.19)$ for the shorter period. This estimate of the EIS is higher and more precise than the ones obtained with just one price index (see Sec. VB). In both columns the Sargan test of overidentifying restrictions does not reject the null.

If we add to the chosen specification the rate of growth in labor income, as in table 3 , its coefficient is small and insignificant. It is worth noting that first-stage regressions produce a reasonably high

\footnotetext{
${ }^{27}$ No attempt is made to correct the standard errors for the use of generated regressors.
} 
TABLE 6

Euler Equation for Total Consumption Expenditure (Using Stone Price Index to Deflate Total Nondurable Expenditure)

$\Delta \frac{\ln \left(c_{t+1}\right)}{b\left(p_{t+1}\right)}=\psi+\sigma\left\{r_{t+1}^{*}-\Delta \ln b\left(p_{t+1}\right)-\Delta\left[\ln \left(c_{t+1}\right)-\frac{\ln \left(c_{t+1}\right)}{b\left(p_{t+1}\right)}\right]\right\}+\theta \Delta z_{t+1}$

\begin{tabular}{lcc}
\hline \hline & $\begin{array}{c}1981: 3-1990: 4 \\
(\text { Cohorts } 1-8 ; N=288)\end{array}$ & $\begin{array}{c}1982: 3-1990: 4 \\
(\text { Cohorts } \\
1-8 ; N=256) \\
(2)\end{array}$ \\
\hline Real interest rate & $(1)$ & .668 \\
.43 & .559 & $(.189)$ \\
$\Delta \log ($ famsize) & $(.224)$ & 1.619 \\
.17 & 1.351 & $(.340)$ \\
$\Delta$ children & $(.357)$ & -.487 \\
.18 & -.498 & $(.155)$ \\
$\Delta w w$ & $(.156)$ & -1.469 \\
.12 & -.816 & $(.967)$ \\
$\Delta \ln (w l)$ & $(.442)$ & -.696 \\
.09 & -1.437 & $(.751)$ \\
$\Delta$ single & $(.835)$ & -1.211 \\
.08 & -1.214 & $(.828)$ \\
Sargan criterion & $(.712)$ & 18.40 \\
$(p$-value) & 17.18 & $(.56)$ \\
\hline
\end{tabular}

NotE.-See the note to table 3 .

$R^{2}$ for all explanatory variables, including labor income growth (for which $R^{2}=.24$ ). When we exclude all demographic and labor supply variables, the coefficient on income is much larger and significantly different from zero. This result confirms that the lack of excess sensitivity is not due to the inability of our instrument set to capture income growth variability.

A comparison of tables 3 and 6 indicates that the explicit consideration of aggregation over commodities is important: point estimates of a key behavioral parameter (the EIS) are larger and more accurate. The estimate of $\sigma$ in the shorter sample goes from 0.48 to 0.67 , and its estimated standard error drops from 0.28 to 0.19 .

Hall (1988) has argued that a proper choice of instruments leads to small estimates of the elasticity of substitution of consumption. Using aggregate data, Hall finds values for the EIS close to zero. Runkle (1991) reports estimates of the EIS of approximately 0.45 using micro data on food consumption. We have shown that a specification of the Euler equation estimated on micro data and total nondurable consumption yields even higher estimates, especially when explicit allowance for nonhomotheticity is made. 


\section{Conclusions}

In this paper, we have shown that the intertemporal model of optimizing behavior for consumption is consistent with U.S. micro data. Our results contrast sharply with most of the existing literature in which theoretical predictions are rejected (Hall and Mishkin 1982; Zeldes 1989). The contrast is even sharper with papers that use aggregate time-series data (Hall 1988; Campbell and Mankiw 1989). We have shown that these differences can be explained either by the use of a very poor proxy for total consumption (food) or by aggregation problems.

It is crucial to the empirical success of the model that preferences are modeled so as to take into account changes in family composition and labor supply behavior over the life cycle. As we recognize in the empirical analysis, such factors are not necessarily exogenous. Modeling fertility and labor supply is beyond the scope of this paper, and our analysis is therefore limited to the estimation of conditional preferences.

The introduction of demographic and labor supply variables as determinants of the discount factor may be open to criticism. It could be argued that the large number of parameters we estimate reduces the power of standard tests of overidentifying restrictions or of tests of excess sensitivity of consumption to income. If income is affected by severe measurement error, then demographic and labor supply variables may capture the correlation between expected consumption and expected income, which would imply a rejection of the model. Furthermore, the sign and size of the coefficients on the demographic and labor supply variables might be difficult to interpret.

The answer to these criticisms requires a further step, which we do not take in this paper. To establish whether the coefficients on demographics (and labor supply) are sensible, one should derive the consumption patterns implied by the estimated parameters, given "reasonable" demographic profiles as well as income and interest rate patterns. In a recent paper, Attanasio et al. (1995) show that a life cycle model similar to that presented here is able not only to generate the hump-shaped life cycle consumption that we observe in reality, but also to explain the differences in the shapes of life cycle profiles across education groups. This sort of evidence goes some way toward proving that the preference specifications we estimate are reasonable.

We have devoted considerable attention to the issue of aggregation over different commodities. We have shown that ignoring it can considerably affect the estimates of some key behavioral parameters and 
in particular of the elasticity of intertemporal substitution. This is to be expected if we consider that preferences might not be homothetic (as shown in the analysis of the demand system) and that there have been large changes in relative prices over the 1980s. On the other hand, ignoring the aggregation over commodities does not lead to a rejection of the model.

The answer to the question posed in the title of this paper is a qualified yes. We have shown that some of the implications of an intertemporal optimization model cannot be easily rejected. However, we are aware of the limitations of our methodology. As Deaton (1992) has pointed out, tests of the life cycle model based on consumption growth might fail to detect the presence of operative liquidity constraints since they affect the Euler equation only when they are binding. More generally, the Euler equation approach, while enabling us to estimate key behavioral parameters, does not provide much information on the level of consumption and, therefore, on saving.

There are several directions in which the present research could and should be developed. We believe that more work is necessary to model the relationship between consumption and labor supply. In this paper, we have estimated only conditional preferences. It is important and useful, however, to model household labor supply choices in a rigorous fashion. Furthermore, several aspects of the consumer optimization problem, which were considered only marginally or ignored in this paper, are clearly crucial for a complete understanding of saving and consumption behavior at both the macro and micro levels. An obvious example is expenditure on durables, which is the most volatile component of consumption expenditure over the business cycle. Other important issues are the behavior of the elderly, expenditure on housing, health, and education, and so on.

Given all these qualifications, however, we claim that the intertemporal optimization model of consumer behavior cannot be easily dismissed and constitutes a useful starting point for the understanding of individual and aggregate consumption expenditure.

\section{Appendix}

\section{Estimation and Inference}

The use of synthetic panels constructed from relatively small cross sections induces measurement error in the levels, which in turn implies an MA(1) structure in the first differences. The reason for this is obvious. If the sample for a given quarter $t$ includes a very rich household, this will induce a positive measurement error in the consumption growth at time $t$ followed by a negative measurement error at time $t+1$. The error of equation (1) is therefore going to be made of two components: a white-noise component that reflects 
expectational errors and an MA(1) component with a coefficient of -1 . The sum of a white noise and an MA(1) is an MA(1). The size of the coefficient of this MA(1) depends on the relative magnitude of the variances of the expectational error and of the measurement error. ${ }^{28}$ The presence of measurement error induced by small cell size is relevant for all the householdspecific variables, even for those, such as family composition, that could conceivably be considered as exogenous. ${ }^{29}$

If we ignore the rotating nature of the panel and use all the households in the construction of the relevant variables and the instruments, we get inconsistent estimates in the presence of household-specific fixed effects. On the other hand, using only one interview per household involves the loss of a substantial amount of information.

To get around this problem, we use all observations in the construction of the variables that enter our regression and select subsamples on the basis of the interview number in the construction of instruments. Namely, we use only households at the fourth interview in the construction of lag 2 instruments, we use households at the fourth and third interviews for lag 3 instruments, and we exclude households at the first interview for lag 4 instruments. This scheme guarantees that there is no overlap between the households used in the construction of the instruments and those used in the construction of the variables that enter the estimated equation.

An issue that arises when more cohorts are considered simultaneously concerns the treatment of the instruments. In principle, we could "stack" the instruments for each cohort (effectively imposing the same reduced form for all cohorts), or we could have different first-stage regressions for each cohort. Given the limited number of observations, we decided to stack the instruments (for a discussion of these issues, see Attanasio and Browning [in press]).

As stated in the text, the construction of an efficient instrumental variable estimator has to take into account the presence of MA(1) residuals for each group used in estimation and the contemporaneous correlation among the residuals of the different groups. ${ }^{30}$

In the computation of the standard errors, a further difficulty arises because the variance of the measurement error component of the residuals is a function of cell size. Variable cell size, therefore, may induce a substantial amount of heteroscedasticity. We do not specify a model for heteroscedasticity, but allow for it in the construction of the estimator and in the estimation of its standard errors.

${ }^{28}$ Hall (1988) suggests that if the planning horizon is shorter than the frequency of the observed data, the Euler equation has MA(1) errors. The sum of two independent $\mathrm{MA}(1)$ processes is again an $\mathrm{MA}(1)$ process.

${ }^{29}$ The only exception is age, which we define as median cohort age, and it is therefore unaffected by sampling variability.

${ }^{30}$ Deaton (1985) shows that the cross-sectional second moments can be used to improve the efficiency of the standard instrumental variable estimator by giving less weight to the instruments more affected by sectional variability. Unfortunately, as noted by Fuller (1987), there is no guarantee that the resulting projection matrix will be positive definite in finite samples. We do not make use of these corrections because of their finite sample unreliability. 
Finally, given the age limitations we impose on our sample, the synthetic panel we use in estimation is unbalanced, in that some cohorts satisfy the age restrictions only after or before a given year. This does not induce selectivity bias (age is exogenous) but requires extra care in computing contemporaneous correlations across cohorts.

We write the estimatable equation as $y=\mathbf{X} \beta+u$, where $\mathbf{X}$ denotes the matrix of $k$ explanatory variables, and $u$ is the error term, which contains both an expectational component and an MA(1) measurement error component. Given this error structure, valid instruments are the exogenous variables in $\mathbf{X}$ (seasonal dummies), other deterministic contemporaneous variables (such as age), and second and further lags of the remaining variables. We denote the instruments matrix by $\mathbf{Z}$ and assume that its columns are $m$ $>k$.

The GMM estimator used in the paper is given by the following expression:

$$
\hat{\boldsymbol{\beta}}=P_{x z}^{-1} \mathbf{X}^{\prime} \mathbf{Z}\left(\mathbf{Z}^{\prime} \hat{\mathbf{\Omega} Z}\right)^{-1} \mathbf{Z}^{\prime} y,
$$

where $P_{x z}=\mathbf{X}^{\prime} \mathbf{Z}\left(\mathbf{Z}^{\prime} \hat{\mathbf{\Omega} Z}\right)^{-1} \mathbf{Z}^{\prime} \mathbf{X}$. Its asymptotic variance-covariance matrix is given by $\mathbf{V}(\hat{\beta})=P_{x z}^{-1}$, where $\Omega$ is an $N T \times N T$ block matrix. Each block on the main diagonal is a $T \times T$ matrix given by the variance-covariance matrix of the residuals of one cohort. These matrices have the diagonal and the band surrounding the diagonal different from zero. This reflects the MA(1) structure of the residuals of each cohort induced by measurement error. Both parameters of these matrices are estimated from the residuals of each cohort and are allowed to be different across cohorts. The off-diagonal blocks of $\boldsymbol{\Omega}$ represent the correlation of the residuals of different cohorts. We assume that only contemporaneous correlation is possible, so that these matrices are diagonal. Furthermore, we assume that this correlation is constant over time.

For this estimator to be feasible, we need an estimate of $\boldsymbol{\Omega}$. This is obtained from a first round of consistent estimates computed using the formula above with the identity matrix instead of $\boldsymbol{\Omega}$. Rather than estimating $\boldsymbol{\Omega}$, we use the first-round residuals to construct an estimate of $\mathbf{Z}^{\prime} \mathbf{\Omega Z}$ robust to the presence of heteroscedasticity of unknown form. This estimate is obtained using the following expressions:

$$
\widehat{\mathbf{Z}^{\prime} \mathbf{\Omega Z}}=P_{0}+\alpha_{1} P_{1}+\alpha_{2} P_{J}, \quad 0<\alpha_{i} \leq 1, i=1,2,
$$

where

$$
\begin{aligned}
& P_{0}=\frac{1}{N} \sum_{j=1}^{N} \frac{1}{T_{j}} \sum_{\tau}^{T_{j}} z_{j, \tau} z_{j, \tau}^{\prime} u_{j, \tau}^{2} ; \\
& P_{1}=\frac{1}{N} \sum_{j=1}^{N} \frac{1}{T_{j}} \sum_{t=2}^{T_{j}}\left(z_{j, t} z_{j, t-1}^{\prime} u_{j, t} u_{j, t-1}+z_{j, t-1} z_{j, t}^{\prime} u_{j, t} u_{j, t-1}\right) ; \\
& P_{J}=\frac{1}{N} \sum_{j=1}^{N} \sum_{i=1}^{N} \frac{1}{T_{j i}} \sum_{t=1}^{T_{i j}}\left(z_{j, t} z_{i, t}^{\prime} u_{i, t} u_{j, t}+z_{i, t} z_{j, t}^{\prime} u_{j, t} u_{i, t}\right)
\end{aligned}
$$


$T_{j}$ is the number of periods over which group $j$ is observed; $T_{i j}$ is the number of periods over which groups $i$ and $j$ are both observed; $N$ is the number of groups; and $\alpha_{1}$ and $\alpha_{2}$ are ad hoc weights used to guarantee that the estimated variance-covariance matrix is positive definite in small samples. This procedure (suggested, e.g., by Fuller [1987]; see also Newey and West [1987] for a case in which $\alpha_{1}$ can be chosen optimally) is arbitrary but does not affect point estimates in a substantial way.

No correction to the variance-covariance matrix is made for the fact that some of the regressors we use are generated from estimated parameters (the demand system).

The Sargan (Hansen) test of overidentifying restrictions is given by

$$
\frac{1}{N \bar{T}} \hat{u}^{\prime} \mathbf{Z}\left(\widehat{\mathbf{Z}^{\prime} \mathbf{\Omega Z}}\right)^{-1} \mathbf{Z}^{\prime} \hat{u}
$$

(where $\bar{T}=\sum_{J=1}^{N} T_{J}$ ), which is distributed as a $\chi^{2}$ with $m-k$ degrees of freedom.

\section{References}

$\rightarrow$ Altonji, Joseph G., and Siow, Aloysius. "Testing the Response of Consumption to Income Changes with (Noisy) Panel Data." Q.J.E. 102 (May 1987): 293-328.

Attanasio, Orazio P.; Banks, James; Meghir, Costas; and Weber, Guglielmo. "Humps and Bumps in Lifetime Consumption." Manuscript. London: Inst. Fiscal Studies, 1995.

Attanasio, Orazio P., and Browning, Martin. "Consumption over the Life Cycle and over the Business Cycle." A.E.R. (in press).

Attanasio, Orazio P., and Davis, Steven J. "Relative Wage Movements and the Distribution of Consumption." Working Paper no. 4771. Cambridge, Mass.: NBER, June 1994.

Attanasio, Orazio P., and Weber, Guglielmo. "Consumption Growth, the Interest Rate and Aggregation." Rev. Econ. Studies 60 (July 1993): 631-49.

$\rightarrow$ Banks, James; Blundell, Richard W.; and Preston, Ian. "Life-Cycle Expenditure Allocations and the Consumption Costs of Children." European Econ. Rev. 38 (August 1994): 1391-1410.

Blundell, Richard W.; Browning, Martin; and Meghir, Costas. "Consumer Demand and the Life-Cycle Allocation of Household Expenditures." Rev. Econ. Studies 61 (January 1994): 57-80.

Blundell, Richard W.; Pashardes, Panos; and Weber, Guglielmo. "What Do We Learn about Consumer Demand Patterns from Micro Data?" A.E.R. 83 (June 1993): 570-97.

Browning, Martin. "Which Demand Elasticities Do We Know and Which Do We Need to Know for Policy Analysis?" Manuscript. Hamilton, Ont.: McMaster Univ., 1987.

Browning, Martin; Deaton, Angus S.; and Irish, Margaret. "A Profitable Approach to Labor Supply and Commodity Demands over the Life Cycle." Econometrica 53 (May 1985): 503-43.

Browning, Martin, and Meghir, Costas. "The Effects of Male and Female Labor Supply on Commodity Demands." Econometrica 59 (July 1991): 925-51. 
Campbell, John Y., and Mankiw, N. Gregory. "Consumption, Income, and Interest Rates: Reinterpreting the Time Series Evidence." In NBER Macroeconomics Annual 1989, edited by Olivier J. Blanchard and Stanley Fischer. Cambridge, Mass.: MIT Press, 1989.

Carroll, Cristopher D., and Summers, Lawrence H. "Consumption Growth Parallels Income Growth: Some New Evidence." In National Saving and Economic Performance, edited by B. Douglas Bernheim and John B. Shoven. Chicago: Univ. Chicago Press (for NBER), 1991.

Chamberlain, Gary. "Panel Data." In Handbook of Econometrics, vol. 2, edited by Zvi Griliches and Michael D. Intriligator. Amsterdam: North-Holland, 1984.

$\rightarrow$ Cochrane, John H. "A Simple Test of Consumption Insurance." J.P.E. 99 (October 1991): 957-76.

$\rightarrow$ Deaton, Angus S. "Panel Data from Time Series of Cross Sections." J. Econometrics 30 (October/November 1985): 109-26.

- Understanding Consumption. Oxford: Clarendon, 1992.

$\rightarrow$ Deaton, Angus S., and Muellbauer, John. "An Almost Ideal Demand System." A.E.R. 70 (June 1980): 312-26.

$\rightarrow$ Flavin, Marjorie A. "The Adjustment of Consumption to Changing Expectations about Future Income." J.P.E. 89 (October 1981): 974-1009.

Fuller, Wayne A. Measurement Error Models. New York: Wiley, 1987.

Gorman, William M. "Separable Utility and Aggregation." Econometrica 27 (July 1959): 469-81.

$\rightarrow$ Hall, Robert E. "Intertemporal Substitution in Consumption." J.P.E. 96 (April 1988): 339-57.

Hall, Robert E., and Mishkin, Frederic S. "The Sensitivity of Consumption to Transitory Income: Estimates from Panel Data on Households." Econometrica 50 (March 1982): 461-81.

Hansen, Lars Peter, and Singleton, Kenneth J. "Generalized Instrumental Variables Estimation of Nonlinear Rational Expectations Models." Econometrica 50 (September 1982): 1269-86.

Hayashi, Fumio. "Tests for Liquidity Constraints: A Critical Survey and Some New Results." In Advances in Econometrics: Fifth World Congress, vol. 2, edited by Truman F. Bewley. Amsterdam: North-Holland (for Econometric Soc.), 1987.

Hayashi, Fumio, and Sims, Christopher A. "Nearly Efficient Estimation of Time Series Models with Predetermined, but Not Exogenous, Instruments." Econometrica 51 (May 1983): 783-98.

$\rightarrow$ Keane, Michael P., and Runkle, David E. "On the Estimation of Panel-Data Models with Serial Correlation When Instruments Are Not Strictly Exogenous." J. Bus. and Econ. Statis. 10 (January 1992): 1-9.

Lusardi, Annamaria. "Permanent Income, Consumption and Precautionary Saving: An Empirical Investigation.” Ph.D. dissertation, Princeton Univ., 1992.

$\rightarrow$ Mace, Barbara J. "Full Insurance in the Presence of Aggregate Uncertainty." J.P.E. 99 (October 1991): 928-56.

Meghir, Costas, and Weber, Guglielmo. "Intertemporal Non-separability or Borrowing Restrictions?” Manuscript. London: Inst. Fiscal Studies, 1991.

$\rightarrow$ Moffitt, Robert. "Identification and Estimation of Dynamic Models with a Time Series of Repeated Cross Sections." J. Econometrics 59 (September 1993): 99-123. 
Newey, Whitney K., and West, Kenneth D. "A Simple, Positive Semi-definite, Heteroskedasticity and Autocorrelation Consistent Covariance Matrix." Econometrica 55 (May 1987): 703-8.

$\rightarrow$ Runkle, David E. "Liquidity Constraints and the Permanent-Income Hypothesis: Evidence from Panel Data." J. Monetary Econ. 27 (February 1991): 73-98.

$\rightarrow$ Zeldes, Stephen P. "Consumption and Liquidity Constraints: An Empirical Investigation.” J.P.E. 97 (April 1989): 305-46. 